\title{
Evaluation of Motion Correction Processing in Equine Bone Scintigraphy by Scheffé's Method of Paired Comparisons
}

\author{
Toshiro YAMAGUCHI ${ }^{1)}$, Yoshiro ENDO ${ }^{2)}$, Yasuo $\mathrm{NAMBO}^{2)}$, Fumio $\mathrm{SATO}^{2)}$, Naoki SASAKI ${ }^{3)}$ and \\ Kazutaka YAMADA ${ }^{3) *}$ \\ ${ }^{1)}$ Gifu University, The United Graduate School of Veterinary Science, 1-1 Yanagido, Gifu, Gifu 501-1193, Japan \\ 2) Japan Racing Association, 535-13 Nishisya Urakawa-cho, Urakawa-gun, Hokkaido 057-0171, Japan \\ 3) Department of Clinical Veterinary Science, Obihiro University of Agriculture and Veterinary Medicine, Inada-cho, Obihiro, Hokkaido \\ 080-8555, Japan
}

(Received 21 March 2012/Accepted 5 October 2012/Published online in J-STAGE 23 October 2012)

ABSTRACT. Equine bone scintigraphy is usually performed with horses in standing position under sedation. However, swaying motion often leads to poor-quality images. To examine the usefulness of motion correction (MC) processing, equine bone scintigrams were evaluated using Scheffé's method of paired comparisons. A significant difference in evaluation scores was detected by analysis of variance (F test, $P<0.01)$. According to all observers, Yardstick analysis scores were higher for images use of MC processing than for those no use of MC processing, for all parts. Overall scores of 5 observers were as follows: without MC $100 \%$ acquisition time (AT, lowest), use of MC with $25 \%$ AT, MC 50\% AT, MC 75\% AT and MC 100\% AT (highest). Thus, MC processing shortens AT in equine bone scintigraphy, and it contributes to a reduction in the external radiation exposure of nurses/technicians.

KEY WORDS: bone scintigraphy, equine, motion correction, Scheffé's method of paired comparisons.

doi: 10.1292/jvms.12-0127; J. Vet. Med. Sci. 75(3): 369-371, 2013

In nuclear medicine scintigraphy, the higher the number of $\gamma$ rays, the better the image quality. Small animals are usually anesthetized during scintigraphy to prevent motion and enable acquisition of a higher count [7]. However, equine bone scintigraphy is usually performed with horses in standing position under sedation [4]. Equine swaying movement under sedation often results in poor-quality images. In recent broadcast, large doses of radiopharmaceuticals have been administered to children in human medicine (www.asahi. com/english/TKY201109010197.html, accessed 2 September, 2011). The concept is "the higher the dosage, the higher the count." This method facilitates rapid counting [3, 6]. A higher dosage results in shorter acquisition time (AT) and lesser movement; however, an excessive dosage may increase internal radiation to patients and external radiation to nurses/technicians at unacceptable levels. Therefore, various sedation methods for preventing swaying movement have been investigated in horses. Combinations of detomidine and acetylpromazine, detomidine and butorphanol and acetylpromazine and romifidine have been reported $[8,9]$. However, even with various sedating drugs and dosages, individual variation in movement is still observed. Image quality in scintigraphy is strongly influenced by the performance of the $\gamma$ camera, radiopharmaceutical characteristics and individual clearance. In addition, accumulation of radioisotopes is difficult to evaluate quantitatively; thus,

*Correspondence to: Yamada, K., Obihiro University of Agriculture and Veterinary Medicine, Inada-cho, Obihiro 080-8555, Japan.

e-mail:kyamada@obihiro.ac.jp

(C)2013 The Japanese Society of Veterinary Science scintigrams are often evaluated subjectively [1]. A motion correction (MC) processing system (MiE, Hamburg, Germany), which corrects for swaying motion immediately, was recently developed to obtain better images without increasing AT and without excessive dosage of radioisotopes [5]. A re-registration algorithm revealed corrected images for viewing simultaneously with the current acquisition, without the need of special hardware devices. The effectiveness of this $\mathrm{MC}$ in improving image quality for diagnosis was tested in this study.

Eleven equine bone scintigrams (technetium-99m-methylene diphosphonate, $1 \mathrm{GBq} / 100 \mathrm{~kg}$ ) collected from equine clinics in Germany were evaluated. Scintigrams involved parts of the head and neck $(n=5)$, body $(n=3)$ and limbs $(n=3)$. Five equine veterinarians (YN, FS, KY, YE and NS) participated as observers in this study. All bone scintigrams were obtained $3 \mathrm{hr}$ after intravenous radioisotope administration. An equine Scanner H.R. (MiE) or SCINTRON-VI (MiE) was used as a $\gamma$ camera. Scintigrams were prepared as follows: no use of MC with $100 \%$ AT represented as MC (-) AT $100 \%$, and uses of MC with 25\% AT, MC 50\% AT, MC 75\% AT and 100\% AT represented as MC (+) AT25\%, $\mathrm{MC}(+) \mathrm{AT} 50 \%$, MC (+) AT75\% and MC (+) AT 100\%, respectively (Fig. 1). In 11 cases, each pair of 5 scintigrams was blindly and randomly displayed on a high-resolution monitor for $10 \mathrm{sec}$. The observers then evaluated the prominence of the hot area of images on a 7-grade scale (left image +3 , left image +2 , left image +1 , center 0 , right image + 1 , right image +2 and right image +3 ). These scores were statistically evaluated using Scheffé's method of paired comparisons [2]. A significant difference in evaluation scores was detected by analysis of variance (F test, $P<0.01)$. Yardstick values for each observer are shown in Fig. 2. Images use of 


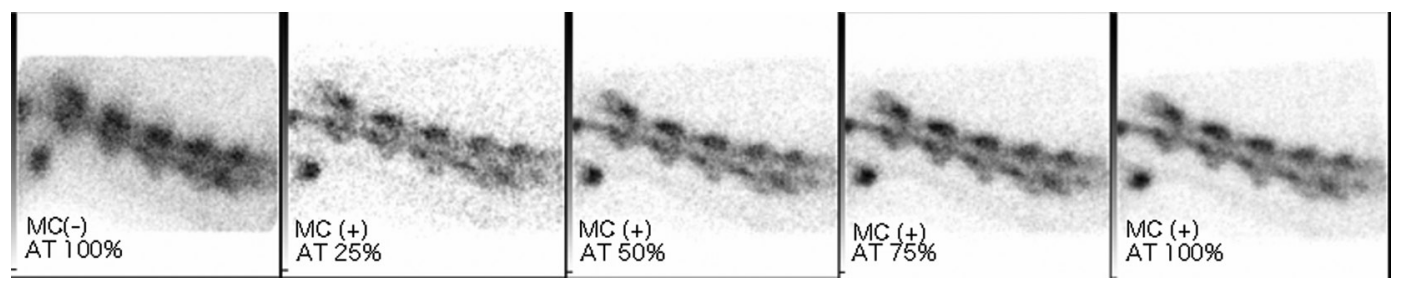

Fig. 1. Representative scintigrams with and without motion correction processing (MC: motion correction, AT: acquisition time).

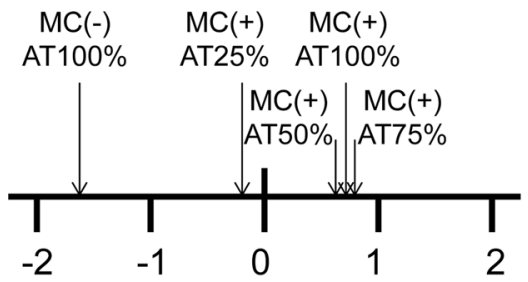

YN

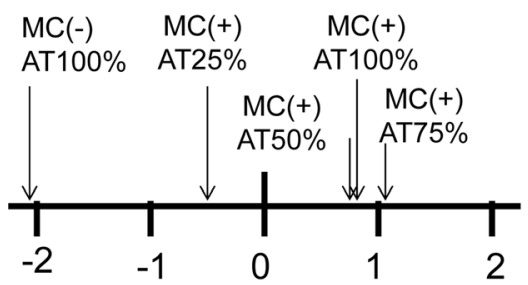

YE

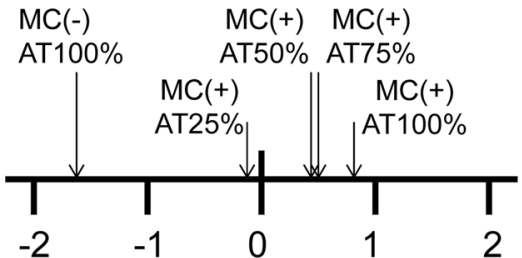

KY

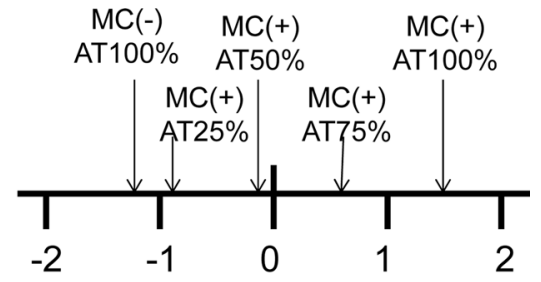

FS

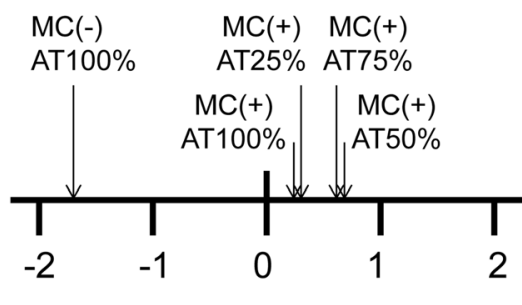

NS

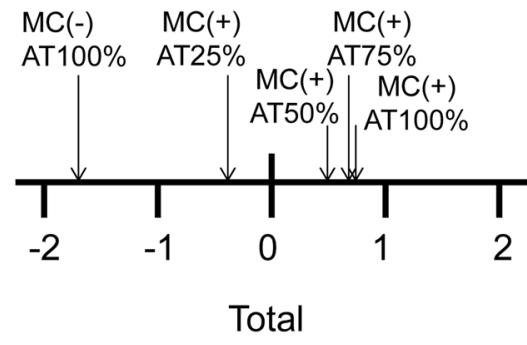

Fig. 2. Yardstick values of equine bone scintigrams for each observer using Scheffé's method of paired comparisons $(P<0.01)$

( $\mathrm{n}=11$; MC: motion correction, AT: acquisition time)

MC processing scored higher than those of no use of $\mathrm{MC}$ processing, according to all observers. Overall scores of all the 5 observers were as follows: MC (-) AT 100\% (lowest), $\mathrm{MC}(+) \mathrm{AT} 25 \%$, MC (+) AT 50\%, MC (+) AT 75\% and MC (+) AT 100\% (highest). MC processing provides clear bone scintigrams, because it involves adjustment of the $\mathrm{X}$-axis, $\mathrm{Y}$-axis and rotation movement of each frame [5]. As a result, even MC (+) AT 25\% resulted in higher scores compared with the scores MC (-) AT 100\%. On the other hand, variations in scores among $\mathrm{MC}(+)$ AT 50\%, MC (+) AT 75\% and MA (+) AT $100 \%$ were minimal. In this study, AT 50\% was considered adequate in MC processing. Yardstick values for head and neck, body and limbs are shown in Fig. 3. Similar to the results of the observer analysis, scores of the Yardstick analysis of equine bone scintigraphy use of $\mathrm{MC}$ processing were higher than those no use of MC processing for all parts. Score variations for the body were larger than those for the head and neck, and score variations for the head and neck were larger than those for the limbs. MC processing was more effective for body images because of the greater movement, while it was less effective for limbs, which typically exhibit less movement. Although MC processing has not been widely available now, we believe that it will distribute in equine scintigraphy near future.

The results of this study indicate that MC processing shorten AT in equine bone scintigraphy. As a result, there 

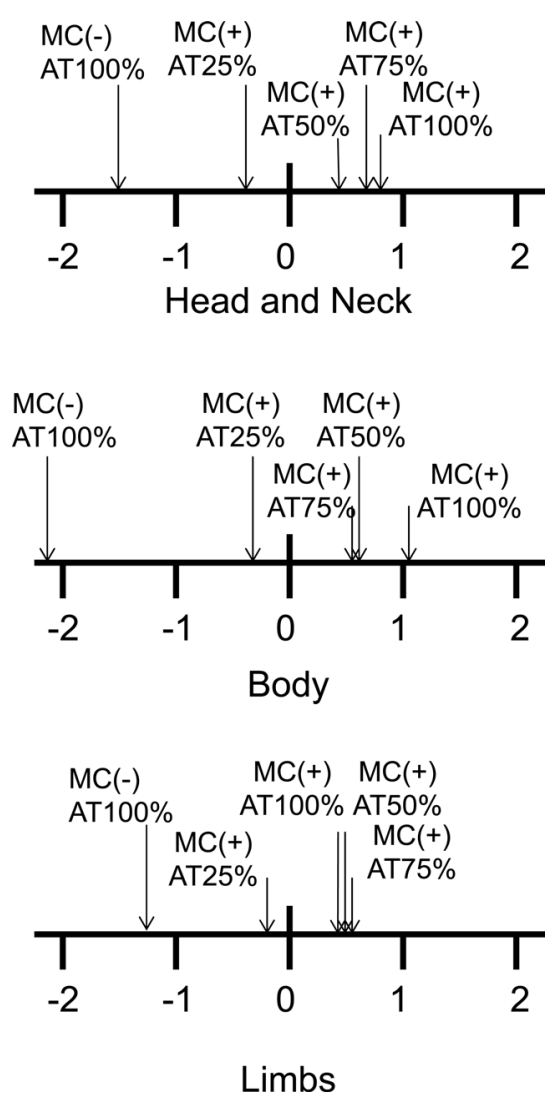

Fig. 3. Yardstick values of equine bone scintigrams for each body part using Scheffé's method of paired comparisons $(P<0.01)$. (MC: motion correction, AT: acqusition time, 5 observers)

is no need to repeat of acquisition impaired by movements. Use of this MC technique also contributes to a reduction in the external radiation exposure of nurses/technicians.

\section{REFERENCES}

1. Arndt, J. W., Crama-Bohbouth, G. E., Verspaget, H. W., Blok, D., Pena, A. S., Tham, R. T. O. T. A., Weterman, I. T., Lamers, C. B. H. W. and Pauwels, E. K. J. 1989. Image quality and radiopharmaceutical parameters of Indium-111 granulocytes in scintigraphy of inflammatory bowel disease. Eur. J. Nucl. Med. 15: 197-200. [Medline] [CrossRef]

2. Nakamae, M., Tabata, Y., Ohga, Y., Kakuta, M., Uto, F., Okunishi, T., Ochi, T. and Maeda, K. 1996. Method of subjective evaluation by Scheffé's method of paired cmparisons. Jpn. J. Radiol. Technol. 52: 1561-1565 (in Japanese).

3. Piepsz, A., Colarinha, P., Gordon, I., Hahn, K., Oliver, P., Roca, I., Sixt, R. and Velzen, J. V. 2001. Guidelines on 99mTc-DMSA scintigraphy in children. Eur. J. Nucl. Med. 28: BP37-41. [Medline]

4. Pilwsorth, R. C. and Dyson, S. J. 2003. Practical scintigraphic examination of the horse. pp. 73-75. In: Equine Scintigraphy (Dyson, S. J., Pilsworth, R. C., Twardock, A. R. and Martinelli, M. J. eds.), Equine Veterinary Journal Ltd., Suffolk.

5. Sarkar, S., Oghabian, M. A., Mohammadi, I., Mohammadpour, A. and Rahmim, A. 2007. A linogram/sinogram cross-correlation method for motion correction in planar and SPECT imaging. IEEE Trans. Nucl. Sci. 54: 71-79. [CrossRef]

6. Stauss, J., Palma, D. D., Hahn, K. and Mann, M. 2010. Guidelines for paediatric bone scanning with $99 \mathrm{mTc}$-labelled radiopharmaceuticals and 18F-fluoride. Eur. J. Nucl. Med. Mol. Imaging 37: 1621-1628. [Medline] [CrossRef]

7. Winter, M. D., Miles, K. G. and Riedesel, D. H. 2011. Effect of sedation protocol on glomerular filtration rate in cats as determined by use of quantitative renal scintigraphy. Am. J. Vet. Res. 72: 1222-1225. [Medline] [CrossRef]

8. Yamashita, K., Kishihara, K., Haramaki, S., Tsukiyama, K., Tagami, M., Izumisawa, Y. and Kotani, T. 1999. Sedative effects of medetomidine, detomidine, and xylazine in horses. J. Jpn. Vet. Med. Assoc. 52: 498-503 (in Japanese).

9. Yamashita, K., Tsubakishita, S., Futaoka, S., Ueda, I., Hamaguchi, H., Seno, T., Katoh, S., Izumisawa, Y., Kotani, T. and Muir, W. W. 2000. Cardiovascular effects of medetomidine, detomidine and xylazine in horses. J. Vet. Med. Sci. 62: 1025-1032. [Medline] [CrossRef] 